\title{
Patients' Perspectives on the Feasibility, Acceptability, and Impact of a Community Health Worker Program: A Qualitative Study
}

\section{Wei Chang}

Community Health Center, Inc. https://orcid.org/0000-0003-4248-3816

May Oo

Community Health Center, Inc.

\section{Adriana Rojas}

Community Health Center, Inc.

\section{April Joy Damian ( $\nabla$ adamian2@jhu.edu )}

Johns Hopkins University Bloomberg School of Public Health, Department of Mental Health - Baltimore, Maryland, United States https://orcid.org/0000-0001-6048-1094

\section{Research}

Keywords: community health worker, patient perspective, social determinants of health, community health

Posted Date: October 21st, 2020

DOl: https://doi.org/10.21203/rs.3.rs-93470/v1

License: (c) (1) This work is licensed under a Creative Commons Attribution 4.0 International License. Read Full License 


\section{Abstract}

Background: Growing evidence suggests that community health workers (CHWs) can play a key role in delivering culturally competent preventive care services, addressing social determinants of health (SDOH), and improving the health outcomes of underserved populations. This study sought to understand the experiences of patients with Type 2 diabetes working with a CHW in a safety net setting.

Methods: A convenience sample $(n=13)$ who participated in a six-month CHW pilot program at a federally qualified health center $(\mathrm{FQHC})$ was recruited for in-person or telephone semi-structured interviews that included 17 open-ended questions regarding patients' experiences with the CHW program. Interview transcripts were analyzed using a traditional text analysis method based on a grounded theory approach to identify themes related to the participants' perspectives of the CHW program.

Results: This study highlights the CHW program can improve satisfaction in accessing health services and community resources, and overall health outcomes of patients in the safety net practices. Moreover, patients discussed the positive impact of the CHW program in terms of improved medical knowledge, access to medical services, and self-efficacy. The CHW's professionalism also helped to establish rapport and trust that further supported behavior changes related to patients' health goals.

Conclusion: Patients' overall positive perception regarding the feasibility, acceptability, and impact of the $\mathrm{CHW}$ program indicated that the intervention may be a viable solution to address the health and social needs of patients in safety net settings. Additionally, CHW programs can help to bridge the gap between patients and healthcare team by mitigating barriers to care.

\section{Background}

Community health workers (CHWs) are trusted members of the community with extensive knowledge about community resources and work as an integral liaison between community members and local services [1]. In the 1950s and 1960s, the U.S. government started a series of "community responsive initiatives," including a comprehensive primary care and community health model for Native Americans. $\mathrm{CHWs}$ were an integral part of the collaboration with the Navajo Tribe because they helped to reduce cultural barriers and serve in nursing capacities [2]. Since the development of this early intervention, the role of $\mathrm{CHWs}$ has expanded to include health education, counseling, navigation assistance, social support and advocacy $[1,3]$. Serving a critical role in the frontline healthcare team by improving health outcomes and reducing healthcare costs, the overall employment of $\mathrm{CHWs}$ is projected to grow 10 percent from 2018 to 2028, outpacing the average growth rate for all occupations [4]. As the demand for CHWs continue to grow, there is a need for a deeper understanding of how to support effective integration of CHWs into diverse healthcare settings $[5,6]$.

Recent studies have found a wide range of positive outcomes associated with implementation of a CHW intervention program. Evidence from randomized clinical trials suggest $\mathrm{CHW}$ interventions led to improved health outcomes, better quality of care, and reduction in hospitalizations [7, 8, 9]. Moreover, 
standardized $\mathrm{CHW}$ interventions demonstrated a promising return on investment of $\$ 2.47$ for every dollar spent annually [10]. Similarly, systematic reviews of $\mathrm{CHW}$ interventions suggest that $\mathrm{CHW}$ interventions can significantly reduce healthcare utilizations and cost as well as provide cost-effective interventions for certain health conditions, especially among underserved populations $[3,11]$. One study of Latino adults with Type 2 diabetes managed at a federally qualified health center (FQHC) found that the participants in a six-month $\mathrm{CHW}$-led diabetes self-management education program showed a statistically significant decrease in $\mathrm{A}_{1 \mathrm{c}}$ levels and in diabetes distress compared to participants in the control group (enhanced usual care) [12]. Moreover, research suggests that $\mathrm{CHW}$ integration into healthcare teams of a FQHC demonstrated positive intervention effect on patient activation and patient health outcomes, including $A_{1 c}$, non-HDL cholesterol and depressive symptom scores [13]. However, despite a growing body of literature on how CHWs can improve health outcomes and decrease healthcare utilization, there is limited evaluations and knowledge around the effectiveness of CHW programs that is based on patients' perception. Thus, there is a need for research that examines the feasibility, acceptability, and impact of the pilot $\mathrm{CHW}$ program in a safety net setting.

The present study focuses on patients who have participated in the $\mathrm{CHW}$ pilot program to 1) explore patients' perspectives on the feasibility of the $\mathrm{CHW}$ program, including the timing and frequency, location, and attendance at sessions, 2) understand the acceptability of the CHW program from the patients' point of view, specifically with respect to the format and content of the intervention, and in comparison to other available supports, and 3) evaluate the impact of the CHW program, particularly in the areas of patients' knowledge of and access to medical and community resources, relationship with the healthcare team, as well as the program's impact on patients' social support, self-efficacy, and patient-stated goals.

\section{Methods}

\section{CHW IMPaCT Model Design}

Community Health Center, Inc. $(\mathrm{CHCl})$ is a $\mathrm{FQHC}$ based in Connecticut providing comprehensive primary care services in medicine, dentistry, and behavioral health for more than 145,000 patients. $\mathrm{CHCl}$ has adopted the outpatient IMPaCT approach, which is a six-month engagement for patients where they work with a CHW to achieve their stated health goals. The IMPaCT Model is an approach to standardizing and scaling $\mathrm{CHW}$ integration developed by the Penn Center for Community Health Workers [14]. $\mathrm{CHCl}$ implemented the IMPaCT CHW Intervention that aligned with the priorities of Connecticut's State Innovation Model (SIM). Connecticut's SIM is a strategic model that aims to not only improve population health and health outcomes but also to reduce health disparities and healthcare costs [15]. The CHW intervention consists of two key components: 1) "Meet the Patient Interview," through which the CHW can learn more about patients and understand patients' goals, and 2) integration of the CHW into the clinical care team, which allows the CHW to access and document in the patients' electronic health record. Moreover, the $\mathrm{CHW}$ facilitates the communication between the patients and the providers. While spending time with the patients outside of the clinical setting, the $\mathrm{CHW}$ can see firsthand the daily challenges that 
patients experience and observe barriers that may be preventing the patient from living his or her healthiest life.

\section{Participants}

A 27-week CHW intervention (January-July 2019) at CHCl's Meriden clinical site included 31 adults aged 18 or older diagnosed with Type 2 Diabetes (with an $\mathrm{HbA}_{1 \mathrm{c}}$ greater than or equal to 8) and indicated English or Spanish as their primary language. Eligible individuals completed a six-month intervention that included multiple clinic visits, home visits, and telephone calls from CHW to promote physical activity, healthy eating, and access to community resources. All patients $(\mathrm{N}=31)$ that participated in the $\mathrm{CHW}$ pilot intervention were invited by the research team to participate in a study designed to obtain their feedback on the CHW program. Patients who called the research line to opt-out of the study were excluded. This study was approved by the $\mathrm{CHCl}$ Institutional Review Board.

\section{Procedure}

A subset of eligible participants $(n=13)$ who previously enrolled in the CHW program provided consent to participate in the study. Semi-structured interviews were conducted with consented patients to understand, from the patients' perspectives, their experiences in the pilot $\mathrm{CHW}$ program designed to lessen negative social determinants of health $(\mathrm{SDOH})$ risks and to assist patients in achieving their stated health goals. For the convenience of the study participants, the interviews took place either in-person at the $\mathrm{CHCl}$ Meriden clinical site or by phone in October 2019. Each interview lasted approximately one hour and was scheduled based on the patients' availability. The interviews were conducted in the participants' preferred language (English or Spanish) and subsequently transcribed in English. The interview guide is available in the appendix (Appendix 1) (Appendix 1 should appear at the end of the manuscript).

\section{Data Analysis}

Data from the semi-structured interviews were analyzed from November-December 2019. Interview transcripts were analyzed using a traditional text analysis method based on classic grounded theory [16]. The construction of traditional text analysis involves identifying themes from the interview transcripts, marking up the texts that relate to the themes of the research, eliminating the texts that are not related to the subject of the research, and sorting them into thematic categories $[16,17,18]$. Two researchers first coded independently, followed by mutual discussions with the principal investigator to ensure the accuracy of coding. Through the discussion, codes were mutually agreed upon and sorted into themes.

\section{Results}

\section{Patient demographics}


Table 1 includes a summary of demographics of the sample $(n=13)$. In the present sample, the average age of participants was $56(S D=9.2)$. The majority of participants identified as female $(69.2 \%)$ and Hispanic or Latino (69.2\%).

Table 1

Participant Demographics

\begin{tabular}{|ll|}
\hline & Patients $(\mathbf{n}=13)$ \\
\hline Gender & $\mathrm{n}(\%)$ \\
\hline Male & $4(30.8)$ \\
\hline Female & $9(69.2)$ \\
\hline Age & $56( \pm 9.5)^{\mathrm{a}}$ \\
\hline Race & \\
\hline White & $4(30.8)$ \\
\hline Unreported/Refused to Report & $7(53.9)$ \\
\hline Other Race & $2(15.4)$ \\
\hline Ethnicity & \\
\hline Hispanic or Latino & $9(69.2)$ \\
\hline Not Hispanic or Latino & $4(30.8)$ \\
\hline aMean \pm Standard Deviation & \\
\hline
\end{tabular}

\section{Patients' perspectives on the feasibility of the $\mathrm{CHW}$ program}

Participants talked about the feasibility of the CHW program, including timing of the sessions, frequency of interaction with $\mathrm{CHW}$, location of meetings, and reasons behind missed session(s) (Table 2). The results suggest an overall satisfaction with the length of the program, flexible location arrangements, and flexibility in scheduling. All participants $(n=13)$ reported that the timing and frequency of sessions were adequate. With regards to the location of the engagements, the majority $(n=10)$ mentioned the clinic as a convenient location for them to meet. However, three participants preferred their home as the primary location for meet-up given their health conditions. Additionally, 11 out of 13 participants had missed 
meetings due to forgetfulness $(n=1)$, work schedule $(n=3)$, transportation issues, mobility issues, and health conditions $(n=7)$.

Table 2

Outcomes related to feasibility of the Community Health Worker Program

\begin{tabular}{|ll}
\hline Themes & Participant Quotation \\
$\begin{array}{l}\text { Timing and } \\
\text { Frequency of } \\
\text { sessions }\end{array}$ & $\begin{array}{l}\text { "Length of the program, like that interaction so would like it to be longer." } 02 \\
\text { "100! She always made sure that it was convenient for me. It wasn't about her or } \\
\text { her schedule. She always made sure it was good timing. I met with her as much as I } \\
\text { needed. Maybe once a week, but if I called her and needed her we met more." 06 } \\
\text { "Even when we are not meeting in person, I know I can still call her and connect by } \\
\text { phone should I need assistance with anything." } 17\end{array}$ \\
$\begin{array}{l}\text { Community } \\
\text { venues versus } \\
\text { clinical } \\
\text { settings }\end{array}$ & $\begin{array}{l}\text { "Yes, it's fine for me to meet her at the clinic. Whenever I have trouble meeting her } \\
\text { there, she's willing to make other arrangements so we can meet." 07 }\end{array}$ \\
& $\begin{array}{l}\text { "Sometimes we met in person at the clinic, and sometimes at home. Sometimes } \\
\text { she would come to my place since it was convenient. Also, when I'm not able to go } \\
\text { to the clinic, she comes to my place since she knows my breathing and mobility } \\
\text { issues. I would prefer to meet with the CHW more often at my place my health } \\
\text { conditions since it's sometimes difficult for us to meet in person at the clinic." 09 }\end{array}$ \\
\end{tabular}

Attendance at

sessions

Forgetfulness "Sometimes he forgets he has an appointment with her. Sometimes he missed session because he forgot, having a piece of paper and call the day of the appointment is helpful." 01

Work schedule "Yes, sometimes l've had to miss sessions due to last-minute needs or emergencies at work." 11

Transportation issues, mobility issues, and health conditions
"Sometimes I wasn't able to meet her at the clinic because I didn't have transportation or because I had trouble with my mobility since I've had an amputation due to my diabetes." 09

"Sometimes I'm not feeling well, sometimes I feel lightheaded or have a headache related to my diabetes, so I have cancel my session with her." 12

"Yes, but in these instances, I would call her in advance and reschedule. Also, if I couldn't physically come to the clinic because l've been very sick, my arthritis makes it very difficult to get around, even getting out of bed is difficult, and causes a lot of pain. She's willing to meet me at home though so we are able to get together." 13

\section{Patients' perspectives on the acceptability of the CHW program}


Participants shared perspectives on the acceptability of the CHW program, specifically on the content, perception of the $\mathrm{CHW}$, comparison to other available non-medical supports, and key recommendations for improving the program (Table 3) (Table 3 should appear before the next subheading). Participants also spoke positively about the usefulness of the program, the CHW's professionalism, and their desire to see the program expand. 
Table 3

Outcomes related to acceptability of the Community Health Worker Program

\section{Themes Participant Quotation}

Content

"Leonora is the best thing that ever happened to me. When I first met her (oh my god I'm going to cry). When I met with her I was at the lowest point in my life. I am usually the one to help people and I was embarrassed that I needed help. She told me that there's nothing to be embarrassed about and that I'm here to help you." 06

"I know I can always call her for whatever I need, for example, if I need help getting to my medical appointments, or filling out paperwork related to social security, especially since English is not my native language so I have challenges understanding what they are asking me in the paperwork and how to complete it." 07

"The program has helped me a lot because she understands me very well, she's helped me from everything from managing my diabetes, becoming more physically active, and just feeling better about myself." 11

"For me, it's helped me tremendously because l've been worried and overwhelmed by my health. I get help from everything from scheduling and rescheduling my health appointments, keeping track of my medications and taking them correctly, and just understanding how to be healthy." 13

Perception of CHWs
"Positive experience with $\mathrm{CHW}$, if she doesn't know the answer she'll look for the answer and will get back to her within a day or two, very professional." 02

"I have told several family members that they should go see Leonora because from day one she has been keeping track of everything and helping me get what I need. I'm very satisfied. She's amazing at what she does. I didn't think in the beginning that it was going to be a good thing. I thought it was just another appointment but now I look forward to it." 04

"Leonora as a person, she makes the program. Because without a compassionate person like her the program wouldn't work. I miss talking to her and having someone I can unload to without feeling judged. She doesn't judge no matter what. These days lots of people judge you. The only other person like Leonora is my mother." 06

Contrast with other non-medical supports offered
"I don't think there's any comparison since she helps me from everything from understanding my medical issues to having access to transportation." 08

"I'm in another program called Silver Sneakers, but I really can't compare the two. Silver Sneakers focuses on physical activity like Zumba, chair exercises, but the challenge is that I have to go to the YMCA to participate in this program. I don't always have the transportation to get there, nor do I feel comfortable walking by myself given my physical condition. It's more convenient to meet at my place with the CHW program." 12 


\section{Themes}

Key

recommendations

for improving the

program

\section{Participant Quotation}

"I think more people need access to this type of program since it's very personal and holistic." 08

"I would recommend expanding the program so that she's not the only person in this role since there's such a need for patients who have trouble getting to their doctor's appointments, challenges with understanding what the doctor is saying or the doctor's instructions especially since English is not my native language. Also, it's not just the medical needs, but I know I can approach with whatever other needs I might have." 10

"The challenge is that she (the CHW) is only one person and she's having to deal with all of us patients who have such complex and unique needs. I need to go to the pharmacy, get groceries, go to my doctor's appointments, but I know she has other patients to also help, so if she had more support, even a shuttle to get us around so she doesn't have to always drive us around, that would help. I hope they keep this program going since it really is a huge benefit to patients, and that the organization makes an effort to support her (CHW) since it is a lot of work." 12

"I think the program needs to expand since other patients need people like her who are patient and can help navigate the health system since it can be very overwhelming and complex without this kind of support that she provides." 13

All participants $(n=13)$ reported being satisfied with the program, including the usefulness and appropriateness of topics covered, as well as the structure and flow of the program. They expressed how the program caters to the unique needs of individuals and develops patients' capacity by improving knowledge, self-confidence, and self-efficacy through education, social support, and informal counseling. Participants commented on the usefulness of support from the CHW in non-medical areas such as going back to school, taking advantage of a gym membership, language support, and self-esteem. Moreover, all respondents $(n=13)$ were satisfied with the CHW's professionalism, resourcefulness, knowledge, and engagement. Most participants emphasized the CHW's interpersonal skills as a significant facilitator in building a trusting relationship and enhancing motivation for working toward their goals. More specifically, participants conveyed that the $\mathrm{CHW}$ showed great compassion, empathy, and willingness to help participants achieve their goals. Additionally, the CHW's professionalism and personality helped participants feel comfortable sharing their challenges openly. When comparing the $\mathrm{CHW}$ program with other non-medical supports, nine out of 13 participants mentioned they could not compare since they have not received any other supports $(n=6)$ or the focus areas of other programs and interventions were different $(n=3)$. However, they emphasized that the CHW program covered different topics such as healthy choices, diabetes management, and active lifestyles while addressing health-related social needs including transportation issues, homelessness, and food insecurity. In terms of recommendations for improving the program, five participants suggested the expansion of the program, which reflects the need to reach more people who could benefit from the $\mathrm{CHW}$ program by gaining access to the required medical and social support. When asking for recommendations for improvement, the participants commented on the desire for the program to be longer in duration and continue past the six-month period. 


\section{Patients' perspectives on the impact of the $\mathrm{CHW}$ program}

When describing their perception regarding the impact of the $\mathrm{CHW}$ program, participants focused on three major themes: healthcare access and engagement, health-related social needs and resources, and selfefficacy and patient goals (Table 4) (Table 4 should appear before the next subheading). Specifically, patients noted the positive impact of the CHW program on improving medical knowledge, access to medical services, and self-efficacy. Participants stated their understanding of the importance of diabetes management and self-care $(n=10)$, medication adherence $(n=3)$, and keeping medical appointments ( $n$ $=2$ ) have improved as a result of participating in the program, and contributed to the adoption of healthy behaviors. Moreover, participants shared that issues around access to medical services such as appointment scheduling $(n=7)$, medication retrieval $(n=2)$, and transportation $(n=6)$ have shown improvement with the integration of the $\mathrm{CHW}$ program to usual care. Participants also commented on how the CHW not only helped them schedule appointments with established care teams but also introduced them to other services such as physical therapy and nutrition counseling $(n=2)$. Furthermore, related to self-efficacy, participants demonstrated the support of CHW helped reduce anxiety $(n=3)$, boost self-esteem $(n=8)$, and improve the overall patient experience and health outcome $(n=8)$. Many participants also noted that the CHW helped them gain more confidence in their abilities to achieve their goals and overcome challenges $(n=10)$. 
Outcomes related to impact of the Community Health Worker Program

\section{Impact on Healthcare Access and Engagement}

\section{Themes Participant Quotation}

Impact on

medical knowledge
"When she first explained to me that everybody that I see can help me feel better it started to make more sense. She's made me take more time for my health. I work a lot of hours and didn't use to keep appointments. She made me understand why I need to keep my appointments." 04

"I have a better understanding of how to test my blood sugar, how to manage my diabetes, navigate my different medical appointments, and also engage in more physical activity." 08

"I have anxiety, which gets worse when I'm trying to exercise since I get nervous about my condition. However, being with her I know I can stay calm and exercise. I also know how to better manage my diabetes, like understanding how to take my own blood sugar." 12
Impact on access to medical services
"Before, I had challenges with transportation, which made it difficult to always make it to my medical appointments and get around. But, she (CHW) has been so helpful in making sure this is addressed. She's helped me retrieve my medications. She has helped me navigate the referrals I have to other providers since I don't always know how or who I'm seeing and when, so it's helpful to have her organize all my medical appointments." 07

"She calls me with reminders, and it's great that we have great communication with each other. She serves as my translator to help me navigate the health system. For example, sometimes I need help changing my medical appointments or communicating with my health team; she's there to assist me with all of these needs. In addition to my diabetes and bronchitis, I also have arthritis and hypothyroidism, and other health issues. She's helped me navigate the different medical appointments that I have for these conditions, which has been so helpful." 09

"Given my arthritis, she has been so helpful in making sure my physical therapy location is easy for me to get to, and that I'm able to get there with ease. When I needed transportation to get to New Haven for the leg I had operated, she was helpful in finding a way for me to get there." 13

Impact on engagement with healthcare team
"Reached out to PCP and nurse before working with "HW so that has not changed much. Didn't change relationship with PCP or nurse." 01

"My doctors are doing more stuff and tests on my eyes and things. My doctor never suggested them before, I know that for a fact." 03

\section{Impact on Health-related Social Needs and Resources}

\section{Themes Participant Quotation}

Impact on access to healthrelated social needs
"Food stamps, sometimes CHW gives him the bus tickets, sent them by mail. Before joining the CHW program, appointment (substance use clinic) on Wednesdays in Rushford and cannot get back (daughter or sister would drop him off). Now CHW has gotten a bus pass for him and he has a ride back." 01 


\section{Impact on Healthcare Access and Engagement}

Impact on "Resources-there aren't many, which I've always known since I worked for shelters. knowledge Leonora tried to find new resources, but it's hard. She tried to find programs to help of community resources me, but there weren't none." 06

"She's informed me about resources in the community, she's asked me if I need anything in the community, and I've said I don't need them and it's better off for someone who needs them more to have them, but it's still nice of her to ask. She's informed me about resources to help pay for utilities, for example, but I don't really need it. I think someone who is in more need should use these services, but I'm still grateful." 11

"I haven't really needed help with this since I already am enrolled in multiple benefits including Medicare/Medicaid and SNAP." 13

Impact on "I've always had my mom and my kids. I haven't had many friends because they are

social

support always negative. Leonora helped me get comfortable opening up. I talk to my daughter better now and not just argue. I used to worry, worry, worry. Now I give something everything I have and then let it go." 06

"I live alone so sometimes I feel isolated. However, now that I'm in this program, I feel more connected, especially since I'm able to connect my care team on a more regular basis for my diabetes." 08

"I haven't really had any challenges with my social support system, so I can't say she's really helped me in this capacity." 10

\section{Impact on Self-Efficacy and Patient Goals}

Themes Participant Quotation

Impact on self-efficacy
"She had very low self-esteem before. CHW said every woman has something beautiful inside them, stuck in her mind." 02

"She helped me get the confidence to work two jobs to do what I needed to do. She gave me the confidence to help me sell myself and get a job. One thing she always told me is "you got this, don't give up". If I feel like everyone is against me, I remember those words and keep going." 06

"I know I have someone who is willing to help me so I'm not on my own in getting what I need, I know I have someone who is advocating for me in whatever situation I find myself in and I can have faith and confidence that the situation will work in my favor." 13

Impact on patient stated goals
"Oh, it's helped me a lot because first of all my diabetes was out of control and now my diabetes is in a non-diabetic state. She's on top of me! it's good, it's okay. My doctor is surprised because when I first started going there my A1C was at a 13 and now it's a $5 . " 04$

"We worked on housing and self-esteem and getting work. She also helped me with my faith and patience and knowing that where I was at that point in my life was okay and that I needed to keep going and keep fighting. I was homeless and sick when we met. My son had just gone to jail. I didn't think things would get better, but she didn't let me give up. We worked on me getting a job. I'm working almost full time now." 06

"My goal in the beginning was to lose weight, this was the first thing I shared with her. My weight is still fluctuating, sometimes I lose weight, then I gain it back because it's hard for me to get to the YMCA." 09 


\section{Patient engagement in the $\mathrm{CHW}$ program}

Table 5 indicates the evidence of the effectiveness of participating in the CHW program. The majority of patients $(69.2 \%)$ receiving $\mathrm{CHW}$ intervention demonstrated promising improvement in their $\mathrm{A}_{1 \mathrm{c}}$ level, while the remainder of the participants showed unchanged (15.4\%), and increased (15.4\%) $A_{1 c}$ level.

Furthermore, the attendance of the program has a positive impact on patient engagement, allowing patients to meet their stated health goals. The results displayed that the best-performing participants $(61.5 \%)$ were the ones who were present during almost all meetings with $\mathrm{CHW}$. Patients who were contacted over the phone due to their medical conditions or other personal issues reported no significant improvement in their $A_{1 c}$ level regardless of their good attendance. 
Table 5

Patient Engagement in the Community Health Worker Program

\begin{tabular}{|llll}
\hline \multicolumn{3}{|l}{ Changes in participants' HbA $_{1 \mathrm{c}}$ Level and number of missed meetings } \\
\hline Participant ID & $\mathrm{A}_{1 \mathrm{c}}$ at Baseline & $\mathrm{A}_{1 \mathrm{c}}$ at Post Intervention & No. of Missed Meetings \\
\hline 1 & 12.4 & 6.7 & 0 \\
\hline 2 & 9.8 & 9.9 & 6 \\
\hline 3 & 8.1 & 7.8 & 2 \\
\hline 5 & 7.0 & 6.0 & 0 \\
\hline 6 & 10.4 & 7.7 & 0 \\
\hline 7 & 7.7 & 6.6 & 2 \\
\hline 8 & 11.2 & 10.6 & 4 \\
\hline 9 & 6.4 & 5.8 & 6 \\
\hline 10 & 11.6 & 7.8 & 0 \\
\hline 11 & 6.9 & 6.9 & 4 \\
\hline 12 & 14.0 & 14.0 & $1^{*}$ \\
\hline 13 & 8.4 & 9.3 & 6 \\
\hline Characteristics of participants' engagement & 7.9 & $0^{*}$ \\
\hline
\end{tabular}

Patients $(n=13)$

$n(\%)$

$\mathrm{HbA}_{1 \mathrm{c}}$ Level

Decreased $A_{1 c}$ Level

$9(69.2)$

Unchanged $A_{1 c}$ Level

$2(15.4)$

Increased $A_{1 c}$ Level

$2(15.4)$

No. of Missed Meetings

$0-2$

$8(61.5)$

$3-5$

$2(15.4)$

*Patients were contacted over the phone due to medical conditions or other personal problems 


\section{Changes in participants' $\mathrm{HbA}_{1 \mathrm{c}}$ Level and number of missed meetings}

More than 6

${ }^{*}$ Patients were contacted over the phone due to medical conditions or other personal problems

\section{Discussion}

This study offers qualitative insights into patients' perspectives on the feasibility, acceptability, and impact of a CHW program. A CHW program is one-of-a-kind intervention to improve patient's self-efficacy or medication adherence [19], and to increase access to the hard-to-reach population [20]. This study provides evidence that integrating a CHW intervention into primary care in a safety net setting improves patients' satisfaction in accessing health services and community resources, and overall health outcomes. Specifically, this study suggests the effectiveness of the CHW program in the areas of increasing health knowledge and improving access to needed health services and health outcomes, which aligns with previous research $[21,22,23,24]$.

Additionally, the results of this study demonstrate the positive effect of professionalism of the CHW in enhancing patient self-efficacy and trust. With the help of the $\mathrm{CHW}$, patients acknowledged that they built up skills and confidence to achieve their target goals by modifying their lifestyle behaviors, which is consistent with earlier research that documented the benevolent relationship between $\mathrm{CHW}$ and community $[25,26,27]$. This study's findings also suggest that the CHW program serves as a bridge between underserved patients and the healthcare team to address inequalities related to social, physical, and economic conditions of people's lives that affect health status. The CHW not only provides services through one-on-one interactions at the convenience of patients in terms of time, location, and schedule but also helps patients navigate the healthcare system to address and improve the social and health needs of the patient population. By understanding patients' experiences with the CHW program, the findings advocate for improvements and expansion of the $\mathrm{CHW}$ program at $\mathrm{CHCl}$. Beyond $\mathrm{CHCl}$, lessons learned from this study will support other safety net practices to implement a patient-centered $\mathrm{CHW}$ program for medically underserved populations.

This study has several limitations. First, social desirability bias might be an issue since one of the data collectors has exposure to patients. This may have reported a higher patients' perception of and satisfaction with the $\mathrm{CHW}$ program. Comparing patients' stated goals in the semi-structured interview with their baseline goals might mitigate this bias. Second, a small sample size where the majority of the participants identified as female, unreported race, and Hispanic or Latino might affect the generalizability of this study. Nonetheless, six to twelve interviews were sufficient enough to achieve thematic saturation [28].

\section{Conclusion}


With these limitations in mind, the findings from this study have several implications on policy, practice, and research. First, the study highlights how integration of $\mathrm{CHWs}$ into clinical care teams could encourage patient self-advocacy by providing culturally appropriate health education, interpreting services, and healthcare system navigation. However, integration of CHWs into the primary care system require support from state and federal government as both regulator and payer for $\mathrm{CHW}$ programs. Therefore, establishing appropriate funding mechanisms such as grants, incentives, and reimbursement would allow for the sustainability and scalability of $\mathrm{CHW}$ programs within safety net settings. Similarly, healthcare practices working to address SDOH and to promote patient-centered care should invest in $\mathrm{CHWs}$ as extensions of the care team and the role of $\mathrm{CHW}$ needs to be recognized more for their contribution to increase health access and improve health outcomes. Moreover, being able to provide $\mathrm{CHW}$ training on health knowledge, skills for optimum effectiveness working with underserved populations, and toolkits for services is fundamental for operational integration. Further research regarding the solution to common pitfalls of the $\mathrm{CHW}$ program can help improve patient self-advocacy by addressing their medical and social needs, and health outcomes by strengthening the capacity of the $\mathrm{CHW}$.

\section{Abbreviations}

CHW: Community Health Worker; FQHC: Federally Qualified Health Center; $\mathrm{CHCl}$ : Community Health Center, Inc.; SIM: State Innovation Model; SDOH: Social Determinants of Health

\section{Declarations}

\section{Ethics approval and consent to participate:}

This study was approved by the $\mathrm{CHCl}$ Institutional Review Board. Each participant gave informed consent to take part in the semi-structured interviews.

\section{Consent for publication:}

The authors affirm that human research participants provided informed consent for publication.

\section{Availability of data and materials:}

The data generated and/or analyzed during the current study are not publicly available due to participant privacy but are available from the corresponding author on reasonable request.

\section{Competing interests:}

The authors declare that they have no competing interests.

\section{Funding:}

No funding was received for this study. 


\section{Authors' contributions:}

All authors (WC, MO, AR and AJD) contributed to the study conception and design. Semi-structured interviews were conducted by AJD and AR. Interview transcripts were first analyzed by WC and MO, then AJD ensured the accuracy of coding. The first draft of the manuscript was written by WC and MO. AJD and AR provided substantive revisions to the first and subsequent drafts of the manuscript. All authors read and approved the final manuscript.

\section{Acknowledgements:}

We would like to acknowledge Leonora Ortiz for leading a 27-week CHW intervention (January-July 2019) and Tierney Giannotti for providing the efficacy of the program.

\section{References}

1. American Public Health Association. Community Health Workers. 2020. https://www.apha.org/aphacommunities/member-sections/community-health-workers. Accessed 20 January 2020.

2. Longlett SK, Kruse JE, Wesley RM. Community-oriented primary care: historical perspective. J Am Board Fam Med 2001;14(1):54-63.

3. Kim K, Choi JS, Choi E, Nieman CL, Joo JH, Lin FR, et al. Effects of Community-Based Health Worker Interventions to Improve Chronic Disease Management and Care Among Vulnerable Populations: A Systematic Review. Am J Public Health 2016 Apr;106(4):e3-e28.

4. U.S. Bureau of Labor Statistics. Health Educators and Community Health Workers. 2019. https://www.bls.gov/ooh/community-and-social-service/health-educators.htm\#tab-6. Accessed 20 January 2020.

5. Balcazar H, Lee Rosenthal E, Nell Brownstein J, Rush CH, Matos S, Hernandez L. Community Health Workers Can Be a Public Health Force for Change in the United States: Three Actions for a New Paradigm. Am J Public Health 2011;101(12):2199-2203.

6. Chaidez V, Palmer-Wackerly AL, Trout KE. Community Health Worker Employer Survey: Perspectives on CHW Workforce Development in the Midwest. J Community Health 2018 Dec;43(6):1145-1154.

7. Kangovi S. Update on Community Health Workers Project. 2018. https://ldi.upenn.edu/news/video-excerpt-shreya-kangovi-update-community-health workersproject. Accessed 20 January 2020.

8. Kangovi S, Mitra N, Grande D, Huo H, Smith RA, Long JA. Community health worker support for disadvantaged patients with multiple chronic diseases: a randomized clinical trial. American journal of public health. 2017 Oct;107(10):1660-7.

9. Kangovi S, Mitra N, Norton L, Harte R, Zhao X, Carter T, et al. Effect of community health worker support on clinical outcomes of low-income patients across primary care facilities: a randomized clinical trial. JAMA internal medicine. 2018 Dec 1;178(12):1635-43. 
10. Kangovi S, Mitra N, Grande D, Long JA, Asch DA. Evidence-Based Community Health Worker Program Addresses Unmet Social Needs And Generates Positive Return On Investment: A return on investment analysis of a randomized controlled trial of a standardized community health worker program that addresses unmet social needs for disadvantaged individuals. Health Affairs. 2020 Feb 1;39(2):20713.

11. Jack HE, Arabadjis SD, Sun L, Sullivan EE, Phillips RS. Impact of community health workers on use of healthcare services in the United States: a systematic review. Journal of general internal medicine 2017;32(3):325-344.

12. Spencer MS, Kieffer EC, Sinco B, Piatt G, Palmisano G, Hawkins J, et al. Outcomes at 18 months from a community health worker and peer leader diabetes self-management program for Latino adults. Diabetes Care. 2018 Jul 1;41(7):1414-22.

13. Kieffer E, Palmisano G, Guajardo C, Sinco B, Hess K, Campos BM, et al. Integrating Community Health Workers into Interdisciplinary Healthcare Teams in a Federally Qualified Health Center: Outcomes and Patient and Provider Perspectives. In APHA's 2019 Annual Meeting and Expo (Nov. 2Nov. 6) 2019 Nov 4. American Public Health Association.

14. Penn Center for Community Health Workers. The IMPaCT model. 2018. https://chw.upenn.edu/about/. Accessed 14 January 2020.

15. Connecticut State Office of Health Strategy. State Innovation Model (SIM). 2020. https://portal.ct.gov/OHS/Content/State-Innovation-Model-SIM. Accessed 20 January 2020.

16. Bright MA, O’Connor D. Qualitative data analysis: Comparison between traditional and computerized text analysis.

17. Glaser BG, Holton J. Remodeling grounded theory. InForum qualitative sozialforschung/forum: qualitative social research 2004 May 31 (Vol. 5, No. 2).

18. Ryan GW, Bernard HR. Techniques to identify themes in qualitative data. Handbook of Qualitative Research. 2nd ed. Thousand Oaks, CA: Sage Publications. 2000.

19. Allen CG, Brownstein JN, Satsangi A, Escoffery C. Peer Reviewed: Community Health Workers as Allies in Hypertension Self-Management and Medication Adherence in the United States, 2014. Preventing Chronic Disease. 2016;13.

20. Levin JL, Philips Jr BU. Improving Health in Hard-to-Reach Communities. Texas Medicine 2018;114(2):32.

21. Gunderson JM, Wieland ML, Quirindongo-Cedeno O, Asiedu GB, Ridgeway JL, O'Brien MW, et al. Community health workers as an extension of care coordination in primary care: A community-based cosupervisory model. J Ambulatory Care Manage 2018;41(4):333.

22. Lewis CM, Gamboa-Maldonado T, Belliard JC, Nelson A, Montgomery S. Patient and Community Health Worker Perceptions of Community Health Worker Clinical Integration. J Community Health 2019;44(1):159-168.

23. London K, Love K, Tikkanen R. Community Health Workers: A Positive Return on Investment for Connecticut. 2017. 
24. Swider SM. Outcome effectiveness of community health workers: an integrative literature review. Public Health Nursing 2002;19(1):11-20.

25. Kane EP, Collinsworth AW, Schmidt KL, Brown RM, Snead CA, Barnes SA, et al. Improving diabetes care and outcomes with community health workers. Fam Pract 2016;33(5):523-528.

26. Koniak-Griffin D, Brecht M, Takayanagi S, Villegas J, Melendrez M, Balcázar H. A community health worker-led lifestyle behavior intervention for Latina (Hispanic) women: Feasibility and outcomes of a randomized controlled trial. Int J Nurs Stud 2015;52(1):75-87.

27. Norris SL, Chowdhury FM, Van Le K, Horsley T, Brownstein JN, Zhang X, et al. Effectiveness of community health workers in the care of persons with diabetes. Diabetic Med 2006;23(5):544-556.

28. Guest G, Bunce A, Johnson L. How many interviews are enough? An experiment with data saturation and variability. Field methods 2006;18(1):59-82.

\section{Appendix}

\section{Appendix 1 Interview Guide}

Rationale: The purpose of the semi-structured interviews is to understand, from the patients' perspective, the 1) feasibility, 2) acceptability, and 3) impact of the CHC Community Health Worker Program piloted at the Meriden clinical site. Interviews with patients currently enrolled in the $\mathrm{CHW}$ pilot program $(\mathrm{N}=31)$ will be conducted at the conclusion of their engagement in the 6-month intervention. The research team will then triangulate data from the semi-structured interview described here with data collected at baseline from the "Meet the Patient" assessments, to draw conclusions about the CHW pilot program. To our knowledge, this is the first evaluation of a U.S.-based CHW program grounded in the experiences of patients.

[Insert introductory prompt/consent]

\section{Feasibility}

\section{Timing and frequency of sessions:}

How satisfied are you with the timing of your sessions with the CHW? The number of times you met with the $\mathrm{CHW}$ ?

Probe about patient's satisfaction with the timing when the sessions were conducted, including (in)convenience. Probe about how often the patient met with the CHW, and if the frequency was too little/much, adequate.

\section{Community venues versus clinical settings:}

How satisfied are you with where you and the CHW would decide meet? 
Probe about patient's satisfaction with the location of engagements (e.g., clinic, home) as well as modes of interaction (e.g., in person, phone).

\section{Attendance at sessions:}

Was there ever a time you had a meeting scheduled with the CHW and were unable to come? Probe about reasons why patient missed session(s) with $\mathrm{CHW}$.

\section{Acceptability}

\section{Content:}

Please describe your overall experience with the program.

Probe about patient's overall satisfaction with the program, including usefulness and appropriateness of topics covered, as well as structure and flow of the program.

\section{Perceptions of the CHW}

Please describe your overall experience with the $\mathrm{CHW}$.

Probe about patient's overall satisfaction with the $\mathrm{CHW}$, including professionalism, resourcefulness, knowledge, and engagement.

\section{Contrast with other non-medical supports offered}

How would you compare your experience in the CHW program with other types of supports offered?

Probe about how patient's participation in CHW program compared with other similar programs, including what worked well in CHW program compared to other programs and vice versa.

\section{Key recommendations for improving the program}

What are your recommendations for improving the program?

Probe about what changes the patient would recommend implementing (e.g., length, structure, and content of program).

\section{Impact}

\section{Impact on knowledge (medical)}

To what extent, if at all, has your understanding of your medical care improved as a result of participating in this program? 
Probe about changes in patient's understanding of health needs, medical care plan, medications taken/side effects (medication adherence), test results, referrals to specialists, discharge instructions if recently hospitalized.

\section{Impact on knowledge (community resources)}

To what extent, if at all, has your understanding of resources available in the community. available to you improved as a result of participating in this program?

Probe about changes in patient's understanding of community resources (e.g., transportation, childcare, insurance, debt collection, drug and alcohol counseling, food assistance, utilities).

\section{Impact on access to medical services}

To what extent, if at all, has your access to medical services improved as a result of participating in this program?

Probe about changes in patient's ability to access needed medical services. Probe about barriers that may have existed prior to engagement with CHW (e.g., transportation challenges, not understanding care plan), and to what extent these challenges have been addressed through this program.

\section{Impact on engagement with healthcare team}

To what extent, if at all, has your engagement with the healthcare team improved as a result of participating in this program?

Probe about changes in patient's engagement with the healthcare team, including the patient's perception of the Community Health Worker being part of the healthcare team.

\section{Impact on access to health-related social needs}

To what extent, if at all, has your access to health-related social needs improved as a result of participating in this program?

Probe about changes in patient's capacity to access resources that support well-being (see examples of community resources listed above).

\section{Impact on social support}

To what extent, if at all, has your social support improved as a result of participating in this program?

Probe about changes in patient's perception of support from others. Probe about particular types of support systems (e.g., family, friends, community, care team, $\mathrm{CHW}$ ).

\section{Impact on self-efficacy}


How has participating in this program impacted your belief in your ability to succeed in specific situations/accomplish a task?

Probe about changes in confidence in ability to set goals and achieve them.

\section{Impact on short-term goals}

Please describe the progress you've made towards the short-term goals you identified at the beginning of the program.

Probe about specific short-term goals developed at baseline and steps taken to achieve goals. Probe about what supported progress towards short-term goals. Probe about challenges encountered in achieving short-term goals, and what would've been helpful to have in place to overcome identified challenges.

\section{Impact on long-term goals}

Please describe the progress you've made towards the long-term goals you identified at the beginning of the program.

Probe about specific long-term goals developed at baseline and steps taken to achieve goals. Probe about what supported progress towards long-term goals. Probe about challenges encountered in achieving long-term goals, and what would've been helpful to have in place to overcome identified challenges.

\section{Closing}

Is there anything else you would like to share that I haven't already asked?

Thank participant for his/her time. 